\title{
Using Night Vision Camera Robot Based on Internet of Thing
}

\author{
Sarjana ${ }^{1}$ Sholihin $^{1, *}$ Adewasti $^{1}$ Emilia Hesti ${ }^{1}$ \\ ${ }^{1}$ Department of Polytechnic Sriwijaya, Jalan Srijaya Negera, Bukit Besar, Palembang, Indonesia \\ "Corresponding author. Email: sholihin@polsri.ac.id
}

\begin{abstract}
One of the positive impacts of human use of technology is the development in the world of robotics which is currently developing quite rapidly, so that it can help human activities in various fields, such as industry, mining, agriculture, security and even entertainment. The robots used are usually reconnaissance robots that are applied to monitor dangerous industrial areas, and are also used in the military field. As for the advantages of the surveillance robot, namely its mini size makes it easy to do reconnaissance, there is a night vision camera which is able to see every incident in the vicinity and its control can be done from a considerable distance and can be seen when it is dark (night). The latest development of the robot recently emerged an innovation where the surveillance robot can be controlled remotely via the internet to be more efficient and save time. This innovation is called the Internet of Things or IoT. The Internet of Things has emerged due to technological developments, social, economic and cultural changes that require Any time connection, Any Things connection, and Any Place connection. It uses two conditions, namely when it is nighttime, it uses night vision mode, on the other hand, when it is daytime it will use daylight mode. For the second test, measuring the RPM of the robot using a tachometer. In this test using 3 scale variables, the slider value is 400,710 , and 1023. For the slider value $=400,146.5 \mathrm{RPM}$ is obtained, for the slider value $=710$, the value is 233.1 RPM, and for the slider value 1023 the value is 265,9 RPM.
\end{abstract}

Keywords: "Artificial Intelligent, Arduino uno, Embedded System, Modul ESP 826, Internet of thing"

\section{INTRODUCTION}

Robots have very many benefits and have become a part of human life in this modern era, for example in the military which has used a lot of surveillance robots controlled by androids to do jobs that humans cannot do directly to supervise areas. dangerous area in military area. As for the advantages of the surveillance robot, namely its mini size makes it easy to do reconnaissance, there is a night vision camera that is able to see every incident in the vicinity and its control can be done from a considerable distance and can be seen when it is dark (night).

This innovation is called the Internet of Things or IoT. The Internet of Things has emerged due to technological developments, social, economic and cultural changes that require Any time connection, Any Things connection, and Any Place connection.

The application of IoT to robots that is made is as a medium of connecting with the internet network from android to robots remotely. The sender of the command information that will be controlled from the smartphone is in the form of a motion controller, as well as sending information on the position of the robot on the smartphone screen display [1].

\section{DESIGN SYSTEM}

The working principle of the flowchart above begins with initializing I / O constant variable declarations then checking the input data from the Blynk application using a joystick, after the joystick data is received by the robot then the data is converted into a joystick array to Value $\mathrm{x}$, Value $\mathrm{y}$. If the data is not received, the robot stops (standby). 
If the joystick array data received is $\mathrm{X}>0$ then there is a Right Command, where the left motor will go forward and the right motor will reverse, if the joystick array data received $\mathrm{X}<0$ then there is a Left Command, where the left motor will reverse and the right motor will go forward, if the joystick array data received is $\mathrm{Y}>0$ then there is a forward command, where the left motor will go forward and the right motor will go forward too, and if the joystick array data received $\mathrm{Y}<0$ then there is a reverse command, where the left motor will reverse and the right motor will back off. Furthermore, if the robot has been given an order, the robot will generate a PWM value for the motor speed set from the PWN input data. Then there will be data input from the Rotary Encoder, then Interrupt 1 then the RPM input sensor is activated, then calculates the trigger data on the RPM sensor. Then the calculation is converted into RPM speed data, then sends it to the Serial Monitor. Then the robot will check the light intensity, if the daylight conditions are bright then Night Vision Mode is Off, and if the daylight conditions are dark then Night Vision Mode is On. Then the video streaming data is sent to the user to be displayed on Android.

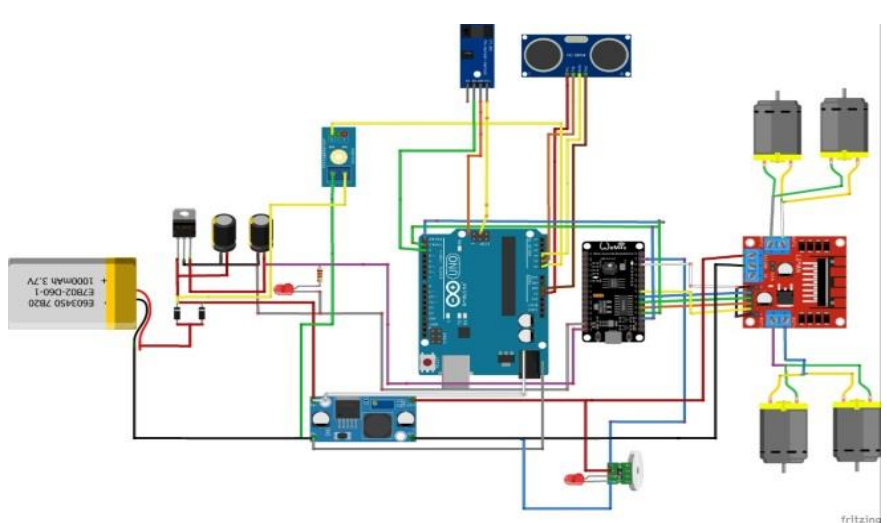

Figure 1 Desain Using Night Vision Camera Robot Based On Internet of Thing

\section{CURRENT RESULT}

In determining the results of the test, the researcher will use 2 scenarios, scenario 1 to determine the results of the night vision camera test in dark and light conditions, for scenario 2 the researcher will test the RPM of the robot's movement with a slder setting of 400, 710 and 1023 .
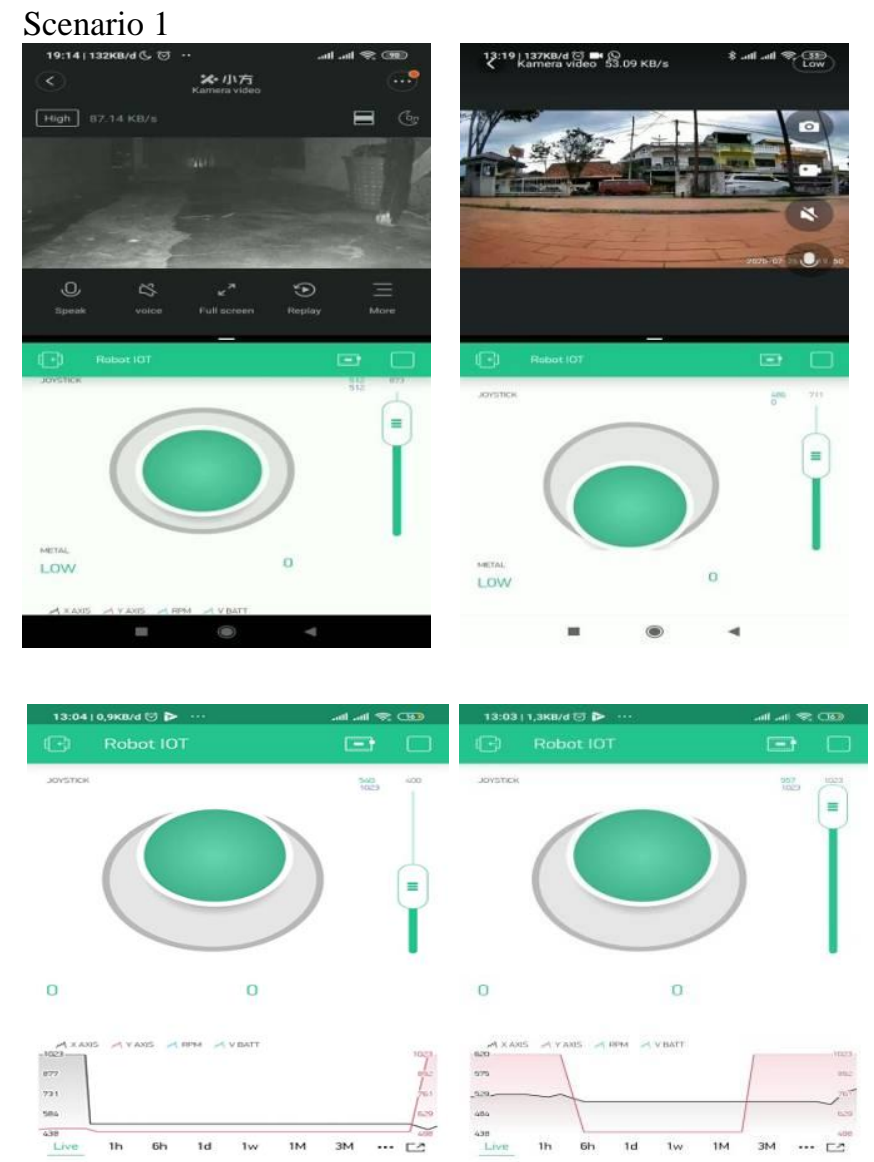

Figure 2 Robot camera in dark and light conditions

Scenario 2

(a)

Slider 400 (b)

\section{Slider 710}

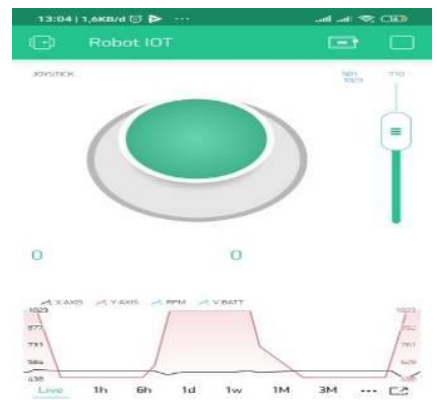

(b) Slider 1023

Figure 3 RPM of the robot's movement with a slder setting of 400, 710 and 1023 


\section{CONCLUSION}

It uses two conditions, namely when it is nighttime, it uses night vision mode, on the other hand, when it is daytime it will use daylight mode. For the second test, measuring the RPM of the robot using a tachometer. In this test using 3 scale variables, the slider value is 400 , 710 , and 1023. For the slider value $=400,146.5$ RPM is obtained, for the slider value $=710$, the value is 233.1 RPM, and for the slider value 1023 the value is 265,9 RPM.

\section{AUTHORS' CONTRIBUTIONS}

Contribution to the authors is making research data collection, with 2 scenarios.

\section{ACKNOWLEDGMENTS}

In writing this paper, the researcher has conducted several sample trials with reference to references as reference material, to improve this paper.

The researcher also thanks the previous authors, and the researcher also apologizes if there are different writing words.

Thank you once again we the researchers say

\section{REFERENCES}

[1]. Craig, J.J. 2005. Introduction to Robotics. Pearson Prentice Hall. Upper Saddle River, New Jersey

[2]. Eka susanti, Rosita febriani, Sholihin, Eka susanti, Emilia hesti, 2018, The design of hand gesture robot software based on wireless technology, IEEE conferences ICOIACT 2018, Indonesia, p.p 401 406.

[3]. Harmalia, Dita. 2015. PENGATURAN OTOMATIS GERAK KAMERA PADA ROBOT PENDETEKSI LOGAM DI AIR TAWAR BERBASIS MIKROKONTROLER ATMEGA 16. Other thesis, Politeknik Negeri Sriwijaya.

[4]. Pitowarno, Endra. 2006. Robotika Desain, Kontrol, dan Kecerdasan Buatan. Yogyakarta: Andi

[5]. Sholihin, Eka Susanti, "Humanoid Robot Control System Balance Dance Indonesia and Reader Filters Using Complementary Angle Value”, E3S Web of Conferences 31, 2018.

[6]. Thangavel, D. 2014. Performance Evaluation of MQTT and CoAP via a Common Middleware, Singapore.

[7]. Waluyo, Yoyo .2015. ROBOT BOAT PENGINTAI BERBASIS ARDUINO DENGAN L293D. Other thesis, Politeknik Negeri Sriwijaya.

[8]. Maulana. I, "Humanoid Robot and Artificial Intelligence, Bandung, 2013, Departement of Computer,STIMIK-AKI, Semarang, 2013. 